Published as: Schäfer, A.I. ; Richards, B.S. (2007) From Concept to Commercialization: Involving Students in a Sustainable Engineering Innovation Project, European Journal of Engineering Education, Volume 32, Issue 2 May 2007 , pages $143-165$

\section{From Concept to Commercialisation: Student Learning in a Sustainable Engineering Innovation Project}

\section{Andrea I. Schäfer*†, Bryce S. Richardsł}

$\dagger$ School of Engineering and Electronics, The University of Edinburgh, EH9 3JL, United Kingdom

¥Centre for Sustainable Engineering Systems, The Australian National University, Canberra, ACT 0200, Australia

School of Engineering and Physical Sciences, Heriot-Watt University, Edinburgh, HW14 4AS, United Kingdom

* Corresponding author. Email: Andrea.Schaefer@ed.ac.uk, Tel: +44 131650 7209, Fax: +44 (0)131 6506781

\section{Abstract}

An interdisciplinary sustainable design project that combines membrane technology with renewable energy to provide water for remote communities and developing countries was offered to students for voluntary participation. Through continuous design stages and improvements on several prototypes, laboratory testing and several field trials in Australia, and interactions with industry partners and funding agencies, the project has offered very important experience to students and contributes significantly to graduate attributes that are difficult to gain during traditional coursework education. Such initiatives offer an exciting addition to the environmental engineering curriculum and can be students gained skills in the areas of team-work and interpersonal skills, project management, interdisciplinary skills, and confidence in interacting with non-engineers.

A number of the students involved who have now graduated as well as peers were subsequently surveyed to evaluate student learning using critical incident questionnaires. One student felt that the involvement in the project was more important than the entire engineering degree. Students reporte also a boost in confidence, motivation, inspiration, pride to be involved, high degree of engagement, especially during field trips. One drawback was negative team experiences, caused by students who thought they should have been selected as project managers. However, this was described by a studen (now in the workforce) as a representation of later office politics and as a good opportunity to develop character strength. Poor communication, team building tools and lack of institutional support were additional issues needing addressing, as well as concerns from other academics that such activities could be to the detiing Industry emphasised the need for more project and time management skills.

Keywords: extracurricular activity, sustainable design, renewable energy, water treatment, holistic engineering education, technology for human development.

\section{Introduction ANd Project Development}

Engineering often suffers from a poor public perception; students perceive engineers as being disconnected from healthy social judgement and unable to interact with the general public in a norma and relaxed manner (Beder 1998). Public perception of what engineers do and what an average engineer is like often result in an outdated 'male, grey and boring' picture. The consequences of this poor perception are severe, with student numbers declining for many years, student quality being lowe than for professions that are perceived as more exciting, and industry finding it difficult to fill challenging positions with suitably qualified graduates. In contrast, engineers have for many decades made very significant contributions to public health, provision of essential infrastructure, and substantial increase in living standards through continuous technological progress. Despite these significant achievements, the divide between rapidly increasing wealth on one hand and the lack of access to . Eck which ren is astonishing (Gleick 202). Eckens divides in today's society, hypothesising that by bringing together the desire of young people for making a difference and the problem solving skills of engineers, the creation a better future is achievable (Eckersley 1999).

The sustainable design project described in this paper aims to contribute to a positive change in the public perception of engineering and attract students with a passion for sustainability and innovation to the engineering discipline. Specific project aims were

- contribute to solving the water provision crisis in a sustainable manner by bringing together research expertise in the areas of water treatment and renewable energy;

inspire students to contribute to solving significant global problems and hence contributing to a better future at the example of sustainability and design; and,

- plant a seed of change for the engineering profession through a interdisciplinary and holistic

project approach in line with the Institute of Engineers Australia engineering attributes (IEAust 1999).

A hands-on learning project was initiated, with the aim of having a team - consisting of undergraduate and postgraduate students as well as academics - develop a sustainable water-treatment system that is powered only from electricity produced by sunlight (Richards and Schäfer 2003). The technology consists of ultrafiltration for particle removal and physical disinfection (removal of bacteria and viruses) followed by nanofiltration or reverse osmosis (desalination and removal of dissolved contaminants such as arsenic). The pump required for filtration is powered by solar energy (photovoltaics). Technical information about the system and optimisation results of various prototypes are published elsewhere (Richards and Schäfer 2002; 2003; Richards et al. 2004; Schäfer et al. 2004; Masson et al. 2005; Richards et al. 2005; Schäfer et al. 2005; Schäfer and Richards 2005; Werner Masso et 201. 20. the first commercial unit has been about 5 years. The different project stages and prototype developments are summarised and illustrated in detail in Table 1 together with an outline of the roles that students and teachers played in the project during the various stages. The project duration naturally resulted in a continuous flow of students joining for varying periods of time. In terms of learning, the student design project, nicknamed ROSI (Reverse Osmosis Solar Installation) was unique in that it

operated outside the undergraduate engineering curriculum;

was interdisciplinary in nature, involving students from varied engineering disciplines (environmental, photovoltaic, electrical, civil) as well as non-engineering backgrounds (physics, finance, marketing); 
- attempted to foster graduate attributes or capabilities that students should possess after completing a 4-year engineering degree;

$\circ$ provided undergraduate students with a taste of engineering research; and,

$\circ$ investigated how such a project could be integrated into an engineering curriculum.

Every student who expressed interest was given the opportunity to contribute, no matter what discipline the student came from or what previous experience they possessed. In general, especially in early stages of the project, students had no prior knowledge of water treatment, renewable energy, or system design. The concept was to inspire students to seek required information independently to better contribute but also generate interest for knowledge to be taught in later subjects. For all students, the project was intended to provide an example of applied engineering and a sense of the usefulness and potential contribution of engineering to the greater community.

This paper outlines the educational experience of the students who were involved the project at This pape oul different ste graduate attibuses cefined by the EAust is highlighed. In paticular, the confontic issues, sustainability and challenging practical problems leads to a holistic engineering education experience. The project is evaluated through the concept of Brookfield's critical incident questionnaire (CIQ) and, to some extent, the four lenses approach (Brookfield 1995).

\section{EDUCATIONAL BACKGROUND}

\section{Desirable Engineering Student Graduate Attributes and/or Capabilities}

The IEAust 'Manual for the Accreditation of Professional Engineering Programs' (IEAust 1999) list the following engineering graduate attributes or capabilities that students should possess at the end of their 4-year undergraduate engineering degre:

ability to apply knowledge of basic science and engineering fundamentals;

ability to communicate effectively, not only with engineers but also with the community at large;

$\circ$ in-depth technical competence in at least one engineering discipline;

$\circ$ ability to undertake problem identification, formulation and solution;

○ ability to utilise a systems approach to design and operational performance,

ability to function effectively as an individual and in multi-disciplinary and multi-cultural teams, with the capacity to be a leader or manager as well as an effective team member

- understanding of the social, cultural, global and environmental responsibilities of the professional engineer, and the need for sustainable development;

$\circ$ understanding of the principles of sustainable design and development;

understanding of professional and ethical responsibilities and commitment to them; and,

$\circ$ expectation of the need to undertake lifelong learning, and capacity to do so.

These are similar to lists of competencies drawn up by engineering organisations in other countries (Shuman et al. 2005; Rouvris et al. 2006) which have classified as cross or transversal competencies, (Shuman et al. 2005; Rouvris et al. 2006) which have classified as cross or transversal competencies,
constituting abilities such as teamwork, project management, lifelong learning, as well as oral and constituting abilities such as teamwork, project management, lifelong learning, as well as oral and
written communication; and, scientific and technical competencies, which are underpinned by skills written communication; and, scientific and technical competencies, which are underpinned by skills
such as designing, problem solving, planning, and developing - all in a cross-disciplinary context. Achieving about half of the IEAust attributes within the traditional engineering curriculum is difficult, in particular the communication with the larger community - the importance of which has also been highlighted by Ravesteijn et al. as the ability to function in multidisciplinary teams; the ability to be a manager or leader; understanding social, cultural, global and environmental responsibilities; the ability to see a project through from conception to completion; and the self-motivation to learn independently and continuously (Ravesteijn et al. 2006). The project described in this paper was designed to deliver progress with the attributes that are difficult to inspire in classroom activities. This required adequate methods to achieve those goals.

\section{Approaches to Achieving Desired Graduate Attributes}

A number of approaches can be found in the literature and are designed to meet the above guidelines for desired student attributes. These include, cooperative learning (CL) (Johnson et al. 1998) and problem-based learning ( $\mathrm{PbBL}$ ) (MacKinnon 1999; Perrenet et al. 2000). CL is an important concept that can be applied to engineering, and such collaborative learning activities have been shown to (T) Pewn to produce significantly higher gains in student learning (Ty approach that can be used to address the growing employer dissatisfaction with graduates' professiona skills (Mitchell et al. 2005), it requires students to determine by themselves what knowledge is required, with the teachers taking the role of giving overviews, guiding discussions, and conducting problem solving tutorials. In such a learning environment, a student is able to acquire knowledge and apply it in a professional environment, improving knowledge and professional problem-solving skills "Developing new products and methods, and applying existing knowledge to new situations is a key professional activity for engineers" (Perrenet et al. 2000). Both students and staff need to adapt to new learning strategies such as PbBL. While students struggle with the lack of direction, unclear boundaries, the possibility of more than one 'right answer', and developing problem-solving and information-seeking skills, academics need to learn to remain 'hands-off', not to overspecify problems, judge when intervention is necessary, and how to fairly assess such projects (Mitchell et al.2005).

When applied to first year students, problem-based activities have shown to increase student interest (D) final year projects (Dym et al. 2005). As an example of how such projects can be integrated into the curriculum, Moore and Berry combine industry-sponsored engineering design projects that are integrated in the curriculum, span over several courses, and bring together formal lectures and informa team discussions. The course contents build on each other and start by developing experience for working in teams, preparing reports and presentations, working on client driven projects and other basic skills that facilitate such projects. Later courses instruct design based on an industrial project specification and industry sponsorship may lead to a senior design project. An academic mentor is available to review drafts and provide feedback to both course instructor and students. Academics are not directly involved in the design to give students full ownership of the project. While academics from outside the course need to be consulted but credits for limited time availability facilitate teaching of scheduling, question preparation and organisation skills The project ends with a design sym that is open to the gesium that is opers as all as the general community (Moore and Berry 2001). Thompson et al. describe how small research project work has con" if long learning" in undergraduate students (Thompson et al. 2005), while Denton points out that such team work, especially when directly relevant to industry, clearly increases student motivation (Denton 1997). In fact, industry insistence for graduates with relevant attributes skills is driving the implementation of problem- or design-based approaches to student learning, although the success of these schemes depends greatly on the facilitation and supervision of the projects or mini-projects. The provision of such intense staff interaction is unlikely in current resource constrained educational institutions, but this constraint can be overcome by using senior students as facilitators (Seat et al. 2001). 
In addition to team work, multi-and inter-disciplinary skills are becoming increasingly important as engineering problems span over several disciplines, both within and outside of engineering. The ability to interact with the broader community becomes critical. Froyd and Ohland have described the concep of integrated curricula to achieve building interdisciplinary links and social links with the community (Froyd and Ohland 2005). Rather than learning individual skills, students in this environment learn the cooperation in a group as a team member; planning and project management skills (working with timelines and schedules); receive peer and teacher feedback; and, teaching other team members (Seat $e$ al. 2001). For students to undertake lifelong learning and have the capacity to do so, a degree of maturity needs to be achieved. An increasing responsibility for students' own learning comes through a gradual relinquishment of the belief in the certainty of knowledge and the omniscience of authoritie (Felder and Brent 2004). Further, students are required to learn the skill to seek information to suppo their julgme Teaching those skills is import their jugg Brolancing ac between suppont an ince appriate height. Conditins that facilitate intellectulgin to be the variety of choice of learning tasks; the explicit communication and explanation of expectations modelling, practice, and constructive feedback on high-level tasks; a student-centred instructiona environment; and, respect for students at all levels of development. All of those conditions can in principle be met by a project based learning activity and in consequence have been applied to this sustainable design project.

\section{Curriculum Integration of Sustainability and Human Development}

For many years professional institutions have been emphasising the need to incorporate sustainability principles into the broader engineering curriculum since engineering solutions often create new environment and aplis develop a sense of social responsibility (Perdan and Azapagic 2003). survey suggests that engineering students possess less-than-adequate knowledge regarding sustainability and while they have difficulties making the connection between sustainable development theory and real-world engineering, the students surveyed did acknowledge that sustainable development was important for engineers (Azapagic et al. 2005). Therefore, engineers need to understand the broader social and cultural context in which they work, and to develop an environmenta sensitivity (Hyde and Karney 2001). Hyde and Karney outline the ways in which engineering education needs to incorporate sustainability principles. A sense of responsibility and personal contro plays a very important role, combined with the skills to "make future decisions for themselves" (Hyde and Karney 2001). Brunetti et al. describe an approach where students worked on a project trying to resolve the environmental problems of a university campus. While the problem itself was not resolved progr" for the integation of sustainabil program" for the integration of sustainability as a critical hiteracy in engineering programs, with both "the role of engin roles (Paten et al. 2005). For example, Rammelt and Boes describe an engineering activity where human development and engineering are combined. Future engineers are exposed to the arsenic contamination problem in Bangladesh by being involved in a consortium that assesses the situation an develops solutions. By doing research on the problem as well as short term field work, the students learn about the integration of disciplines. The project has a positive impact on "students flexibility, ability to work in a team, self-reliance, confidence, open-mindedness, understanding of interrelation between sub-problems, etc." (Rammelt and Boes 2004). Problems observed are the learning-by-doing approach which does not always lead to predicted results in a given timeframe which conflicts with the engineering approach that is outcome rather than process oriented.

Applied to a project for remote community water supply this provides a number of opportunities Firstly, the technology choice needs to be of a sustainable nature. Secondly, waste minimisation, chemicals usage, energy efficiency and water efficiency need to be optimised. Thirdly, the cultural an social context of the implementation of projects needs to be examined. This inevitably leads to the role of technology in human development and poverty reduction. While the notion of appropriate technology has been in the engineering world for some time (Beder 1998), those principles are to date rarely integrated into engineering education.

\section{STUdent LeARning}

To evaluate if the project has been successful in improving the graduate attributes of project participants as anticipated critical incident questionnaires (CIQs) developed by Brookfield (Brookfield participants as anticipated critical incident questionnaires (CIQs) developed by Brookfield (Brookfiel
1995 ) were used. Engaging in this process of continuous professional (as well as personal) development and sharing this process with students is likely to be a very successful path to encouraging development and sharing this process with students is likely to be a very successful path to encouraging
students to themselves also engage in continuous learning. This is in fact one of the graduate attributes as outlined earlier. According to Brookfield "for teachers to be effective they should be aware of how learners experience learning" (Brookfield 1991). CIQs were sent to fifteen graduates that have been involved in the project between 2001 and 2005. The thirteen graduates who were successfully contacted and replied to the questionnaire were the student project manager from stage I, two work experience students from stage I, one honours student from stage I, one student involved throughout the entire period, two European practicum students working for six months on the project full time, two were first year scholars (project being their first exposure to research), one volunteer, one $\mathrm{PhD}$ studen on the project, and two honours students doing their final thesis on aspects of the project. The questions used in the CIQs are listed in Table 2.

\section{Student Learning (Question 2)}

Student perceived their learning in three areas (1) technical contents, (2) personal skills and (3) preparation for an engineering career.

Technically the students learned about membrane technology, photovoltaics, DC pumps, hydraulic design software and water treatment as well as remote community water needs in general. This wa achieved by providing a contaxt for students to acquire the required information. Students recognised the potential of knowledge gained in coursework education and appreciated being involved in a real \& practical engineering project which allowed them to apply theory from coursework. Students emphasised that the holistic approach in this project was very useful as technical, commercial, environmental, social and economic issues were covered while holistic projects in coursework seem ( ( This an renewable potential was given to them through their education and the opportunities of combining skills from different subject areas (which a rarely linked in an engineering curriculum). It is interesting that student identified with the holistic learning experience. Whereas Miller and Boud (Miller and Boud 1995) emphasise the cultural and social context of the learner, of greater relevance here is the holistic nature of the project, students seeing their technical studies in the full social context. 
Social skills gained ranged from personal growth to a better understanding the tasks of academics in an educational institution. Students mentioned that they improved interpersonal skills, teamwork, communication, self-organisation and strengthened their character. They saw their involvement in the project as a personal growth opportunity not normally available until employment to resolve personal issues and challenges. For some of the overseas students English writing skills were gained while others mentioned improved abilities in technical language through communication with suppliers of technical parts as well as better skills for interaction with non-engineers. Other skills gained were problem solving in a practical situation, review related literature in an analytical and critical way (which is a significant challenge for many engineering students, referencing, laboratory and research methods and time management. It should be noted here that many of the learned skills are those 'soft' skills listed in graduate attributes and it is often difficult to integrate the acquisition of such skills into standard curriculum. What students mentioned repeatedly is the dysfunctions of the team which stanch indict 1996). While in (the the important role as one would expect also to be the case in industry.

Learning in this project was seen as a preparation for an engineering career by providing an experience in working on an engineering solution as a team, think more clearly about career choices, taste of wha it would be like to work in industry and understand engineers involvement in research and development. Increased awareness of factors necessary to support technological innovation is an attribute of particular importance for implementation of engineering solutions. One student put it "the biggest skill I would have to offer as an employee would come from my involvement in the project rather than the degree", which was rather humbling. It appears that the project may have given some the sense that they are ready to face the real world, a boost in confidence that is not to be neglected.

\section{Project Contribution to Future Careers (Question 3)}

The contribution of the project to the future career of students can be divided into two categories being (1) practical aspects of career enhancement, and (2) personal skills. The practical aspects were further enhancement of the foundation of the engineering knowledge, a broader view of some aspects and thei importance for the future (water in particular), refinement of problem solving skills to a professiona level, acquisition of knowledge of the research and development process, experience in project work, practical experience in construction and design, as well as valuable work experience. Some student secured a position in industry as a result of the collaboration on the project and others were told that their project involvement had resulted in their hire. Generally students benefited from enhanced employment opportunities as employers were fascinated by the project and impressed with studen Sudents have appreciated the opportunity to involw bad exam results), which appeared to result in a good learning environment and confidence to learn by making mistakes. This freedom inspired independence and to some degree critical thinking. Emotions played an important role in learning as Miller and Boud emphasised (Miller and Boud 1995).

Inspiration, motivation and confidence were the improved personal skills that got mentioned repeatedly. Students appreciated being part of a project from the beginning to the end which involved setting and meeting goals that students identified. Experience in teamwork - how to work with people with different experiences and technical knowledge, and some of the difficulties with working in team. A project environment as this is often the first exposure of students to work with othe disciplines, students at advanced years or doing research. This inevitably widened the perspective of students. Some simply enjoyed having interesting stories to tell, which was especially the case after field trips where they also had exposure to the broader community in our community consultation and demonstration exercises which gave first hand insight into the community perception of the new technology.

It was clear from the questionnaires that the more students contributed and pushed their boundaries the more they gained as individuals. This was particularly the case for the student project manager who started with little knowledge and experience and reported significant gains personally.

\section{Student Contributions (Question 4)}

Students were honest and realistic when identifying their contributions. Expectations towards students were high but little incentive to perform was available as the contribution was voluntary and did not attract academic credit in most circumstances. Adult learning was expected but the authoritarian controls as described by Jerram were intentionally not implemented (Jerram 2002). This created the flexibility for students to contribute in major ways or not at all. Students with little confidence and selfflexibility for students to contribute in major ways or not at all. Students with little confidence and self-
motivation often 'drowned' trying to follow the crowd and subsequently lost interest which lead to a motivation often 'drowned' trying to follow the crowd and subsequently lost interest which lead to a
significant drop out rate (the reason is speculative as the timing also coincided with an increase in the significant drop out rate (the reason is speculative as the timing also coincided with an increase in the
workload through assignments and other academic duties). What students reported was quite in line with the actual contributions made ranging from very little to a very exact description of thei responsibilities (that were often self-assigned).

While some students indeed contributed little and had assumed "passive observer" roles, others were not aware of the significance of their efforts. This was a weakness in the project and the way it was run. Students clearly needed more affirmation of their contributions and volunteers in particular required more allocation of small tasks that they could achieve on their own but are not critical to project progress. Junior and less confident students in particular had difficulties with the level of independence in the project and the lack of guidance. More senior and advanced students or those providing significant efforts were more aware of their contributions, such as management challenges that were significant efforts were more aware of their contributions, such as management challenges that were resolved, procurement of parts that were difficult to get, organise safety training, presentations to Rotary Club - raise community awareness and help fundraise, testing of some cleaning agents that hadn't been tested before, obtain first good test results of the system, construction of the prototype setting up field experiments, water testing and trace element analysis, as well as raising awareness of non-technical factors that need to be considered for project success.

To make such projects more successful in integrating the weaker students who can contribute but lack the confidence at the initial stages, it is likely that an integration of such projects into the curriculum where further support through tutors and lecturers as well as academic incentives can be provided where like their contributions to be and then set this up as a type of learning contract to give a stronger sense like their contributions to be and then set this up as a type
of contribution and hence confidence to those students.

\section{Student Engagement (Question 5)}

Students felt most engaged when they were active participants. This was particularly the case for the project manager who said that she felt always engaged and students participating in field trips felt most engaged there as they had reached the ultimate goal of testing their innovation in a remote community, could use their talents and were removed from distractions of the university environment. Active participation and hence engagement were also strong when training (such as for the use of an analytical 
instrument) took place, when a presentation was delivered or the system explained to others, when something went wrong and a problem needed to be overcome, when results looked promising, an something went wrong and a problem needed to be overcome, when results looked promising, an when teamwork was effective and everyone was moving in the same direction. Some felt most focuse when writing their thesis, others when their contribution was discussed in the overall project contex and the lucky students who got to travel $t$ an award ceremony or conference felt most engaged there.

\section{Student Distancing (Question 6)}

Team problems were a major distancing factor - participants with different opinions regarding the direction of the project who ignored student or academic leadership caused grief "this made me feel powerless and useless as a project manager". Prolonged times without communication or update, when not being able to tell peers how the project was going, planning and discussion about who would do what, unclear assignments, lack of knowledge of assigned tasks (such as using instruments) or technica (of (1) confidence by selchelp. Facing hith wa sometimes an indication of lacking support and communication and more team meetings were identified as a resolve. It is clear that students crave more support and indicate distancing when hurdle are encountered. Galbraith raises the importance of risk-taking and how such encounters with unfamiliar territory contribute to learning and personal growth. It appears that there is a fine line between the level of risk and anxiety encountered and the subsequent distancing (escape) or learning when facing those risks (Galbraith 1996).

Distance was linked by some students to distractions through coursework, laboratory experiments (research), guilt of not being able to donate all time or working commitments, when an important task was completed, when writing a thesis and being confined to books. Important to note here is the inevitable differences in what students like to feel connected - some prefer being in the laboratory, thers prefer not to engag in superiments. This is an advantage of such project effors in that student (a) strength, which is quite realistic with future work opportunities (as long as the readiness to do what needs doing is not
lost).

\section{Instructor Contributions (Question 7)}

When students feel supported in crises or valued by being selected for special roles of responsibility they appreciated guidance. Help with technical or managerial problems, a hand in the lab, a clea direction with regards to the nature of experiments and feedback is generally also experienced as useful. Brookfield noted the level of anxiety and insecurity in some adult learners (Brookfield 1991). Much of this was experienced here with students, especially women, who expressed this more openly. This explains the positive response to support and being selected for a task, which the student may have perceived as outside their reach. Learning will be facilitated here if those fears are expressed and perceived (with some expessed an pexsible tha "inadequate impose students dropped out not due to lack of interest but due to seeing themselves as "inadequate imposers"
as Brookfield names it.

Some students attended special lectures to learn more about the related principles which was seen as a useful contribution by the academic, and so was the creation of the opportunity to go on a field trial "as it gave us a goal to achieve and affirmed the project had a purpose".

\section{Confusing Actions (Question 8)}

Dominating in reasons for confusion were team politics and interpersonal problems. The psychologica environment (Galbraith 1996) was often not inductive to wanting to contribute, which is illustrated by the team politics, and the perceived lack of support and acknowledgement of efforts. The level of importance of this issue was surprising. Most students had difficulty accepting that some participants were able to uns is the project and accepting a female leader was certainly a hindrance to sever were able to un in leaders were prepared for those isses as litlle as the paatipans. Success of the project manager to obtain the position was very puzzling to many team participants. The task of interviewing and selecting a manage was the only formal task that the academic steering committee assumed. While the decision was based on the motivation and interview performance of the candidates, the decision caused significan resentment amongst the two confident but ill prepared competitors as well as more senio (postgraduate) students. None of the candidates had adequate technical or managerial skills, nor were they expected to have those seeing that all candidates were junior undergraduate students. Al candidates had been given feedback and the unsuccessful applicants were given other leadership roles more suited to their perceived abilities.

Poor communication, staffing problems (a recruitment mistake was made with a postdoctoral fellow that fully undermined team morale as this person was paid and supposed to be an expert when he wasn't, which frustated st understanding how prect tension. The issue of grants and project budgets has been difficult to grasp for team members and thi has indicated that those issues should not be kept away from students, who are certainly not aware of costs of such projects (especially salaries!) and this constitutes an important part of learning as well as being equal team players. However this is difficult to realise in the educational structure of an institution where students cannot access grant information.

\section{Surprising Events (Question 9)}

The project was in fact a good preparation of the people problems in the real world, and quite unintentionally so. Problems strengthening people is an important observation and the mental preparation this project manager received. Brookfield describes the empowerment experienced by learners when problematic situations are successfully survived (Brookfield 1991). One student expressed this as "people having other agendas than striving for the team goals and this ruined the team, which caused a lot of stress, anxiety and loss of self-esteem but in retrospect I can laugh about it. eam, which caused a lot of stress, anxiety and loss of self-esteem but in retrospect I can laugh about it. Group dynamics are fascinating and I have since realised that this goes on anywhere, but now I am so much more understanding of it; in the future I can rise above those situations and not let them interfere with my work". Others found it hard to work in a team that constantly changed, which admittedly made it sometime difficult to get things done, while one student was surprised how much time she put into it after coming from a "non-inspiring work environment".

Students expressed surprise that such a project could receive research funding (well they did not see the effort involved!), that the project focused on learning not teaching, how important public relations was, how much literature there is on many technical aspects of the project, how long it takes to plan experiments and really get stated on a thesis.

Surprising also was the lack of support from within the university towards such a project which showed the lack of insight many acalemics have into the impor the labably nom such a project involvement can be. 


\section{Other Comments (Question 10)}

Additional comments transpired a sense of achievement and ownership in the project, as well as need to nurture students who are involved "in an opportunistic" way. How this nurturing should look is difficult as each student has different needs and expectations and in consequence learns their own lessons. This comment remains unresolved and puzzling, as many students who actively engaged felt that they received a lot from the project. More commitment by students is something that was expressed to be desperately needed but also something that has evolved as the project matured. More full time students (PhDs) are now involved as well as senior thesis (MEng) students. While this advances research and commercialisation, the spirit of the project has changed and is no longer the learning activity it was for undergraduates.

The student's comments in a way prefer a directive approach of the facilitator. While in this project The nondirective approach (Boud 1987). Intervention of the facilitator was often indirect as underlying support rather than to call meetings and discipline group members about, for example, team politics. Overall students much appreciated their involvement in the project and remain interested and supportive often beyond graduation.

\section{Peer and Community Perception}

The questionnaires were also sent to eleven "peers" that have been directly involved in or were affiliated in some observer role the project sometime between 2001 and 2005. Those peers were the cofounder of the project, a research fellow, an academic supervisor, a honours co-supervisor, honours, scholars and work experience coordinators, two industry partners, a PhD candidate working on similar project and a very interested, an elderly community member and voluntary project fundraiser Eight of the 'peers' responded to the questionnaires. While the peers covered abroad spectrum from the peers can be found in Table 2 .

\section{Contribution to Engineering Education (Question 2)}

Peers were similar to students in recognising the technical as well as interpersonal skills gained. Technical skills emphasised by peers were more practical however, from designing bits and pieces, field skills (wielding a spanner, finding leaks, etc) to report writing, analytical skills, practical prototype building, organisation of the testing process and the general transfer from theory to practise and experience of real world application. Interdisciplinary aspects were seen as important to appreciate other engineering disciplines (mechatronics vs environmental) and the different skills required to solve an interdisciplinary challenge. Implications of the work were seen as independent learning through active research and the real world application skills they are learning can make a positive difference, (t) international awards gives students hope and the power to believe in ideas".

international awas Pont management skills were most important skills for students to gain in such projects. Potentially this is an excellent opportunity to teach such skills and integrate such projects in the curriculum.

Interpersonal skills seen were public relations, communicating the project to the general public, social aspects, teamwork and the opportunity to work with people from different cultures,
Contributions to Future Careers (Question 3)

Peers commented that bringing engineering out to people is fun and offers the opportunity to make a difference, offering students a different perspective (from developing country aspects to the potential to save lives) and the potential to make greater contributions in the future, a concept of holistic project management, confidence and deeper understanding of an environmental engineering project, skills, potential to apply engineering knowledge in problem solving,

It was pointed out that there is a need to place more emphasise on time management and project skills in engineering education.

Again in those comments the interactions between emotions - such as "gaining the confidence in thei ability to plan and carry out a real life engineering project" or "a solid achievement to boost pride an confidence" - and other skills are important, not only for learning, but also for the preparation for the student's career in industry. The fact that engineering can be fun may even contribute to rising student numbers!

\section{Student Contribution (Question 4)}

A question maybe difficult to judge by the more remote peers, but in summary, energy and passion ("positive energy that people bring has a contagious effect"), new ideas and the will to make the project successful were seen as the main contributions. Peers saw that some students were more motivated than others and that "they didn't know a lot but they committed their time to learn". A high turnover of students meant that everything learnt had to be relearned several times, but clearly participants were seen to genuinely wanting it to succeed.

What needs to be communicated better to those team participants is that their contributions were in fact perceived as such and care has to be taken to deal efficiently with the naturally high student turnover that voluntary projects bring.

\section{Student Engagement (Question 5)}

With peers also the field trips were the clear winner of this question. While students complained a lot about the field trips (lack of beer and generally harsh conditions as well as tight work schedules) the morale and work effort was generally outstanding. Students required skills and knowledge to obtain successful outcome at field trips and in consequence had to be engaged. Students also appeared very successful outcome at field trips and in consequence had to be engaged. Students also appeared very engaged in the laboratory, when giving seminar presentations and during the hands on assembling Hence the areas of engagement are well in line with comments made by the students which can be explained by the clearly visible enthusiasm and outcomes of the field activities and the stories told by participants.

\section{Student Distancing (Question 6)}

Again, perceived from often quite remote peers, hence the responses here are somewhat incomplete and at times cynical such as students being most distanced "when laborious, but important tasks were to be performed". Distancing also occurred after the completion of important tasks such as immediately after the first field trip (many students dropped out at this point) or when team problems occurred.

The value of this question was certainly higher when students themselves were asked. 
The fact that only two academics were involved in the project continuously and offered the only stable, albeit time constraint support, makes it difficult to evaluate this question. This further emphasises the need to provide a more stable foundation for such projects with a number of tutors and technical staff.

\section{Learning Improvement Opportunities (Question 7)}

Possible improvements from this first initiative are plentiful. Better communication from student to students as well as between students and academics in terms of goals and achievements as well as the overall research process would be helpful. In fact, Ramsden names clearly stated academic expectations as a criterion to encourage a deep learning approach, which is somewhat easier if there are awards associated with those goals or expectations (Ramsden 1992). Other suggestions are that time management, record keeping and team skills could be communicated as special classes and that better alignment of goals of supervisors and students need to be achieved.

alignment of goals of supervisors and students need to be achieved. Again it is interesting here how someone aware of the project was quite discriminatory with regards to the incompetence of the project manager "feedback system so ineffective managers can be replaced". The aspect of this issue has saddened and surprised the academic supervisors despite experiencing similar issues in the academic context, as it was not the manager the problem but the undermining from within the team.

A further suggestion was to provide more funding so more students could join the field trips, although field trials were open to any student interested and not funding limited. However, students were requested to contribute to the very modest living expenses to ensure commitment, during the shorter trips.

\section{Curriculae Integration (Question 8)}

Opportunities exist for students to work on the ROSI project as part of their honours or scholars thesis. A further opportunity is to gain credit as work experience. However, beyond those cases students did not receive academic rewards for contributions which necessarily resulted in often non committal efforts. Yet learning was achieved on many levels beyond usual coursework and it appears logical to incorporate such activities in the curriculum. Although it is obvious that integrating those projects with incorporate such activities in the curriculum. Although it is obvious that integrating those projects with
coursework will be an ideal concept, the possibility to replace current classroom courses with such a coursework will be an ideal concept, the possibility to replace current classroom courses with such project based activity and the need to support a project based activity with a classroom style course i not identified by the peers. However, Brookfield (Brookfield 1991) suggests the concept of learning journals, which could be used to integrate such projects in the curriculum and assess contributions. Thi would require a more formal supervision structure which is difficult to achieve with 1-2 academic supervisors for large projects but with adequate tutor support would be achievable. It appears that at some institutions such projects are successfully integrated over several courses, disciplines an supported by several academics, which illustrates the support such activities require (Rouvris $e$ t al. 2006). Other options would be to run small projects during session, large projects during the holidays or assess the project as a group activity as part of the curriculum in adequate courses. Similar topics or asses the project as a could be created as electives for all students, not necessarily research based, but to enhance
independent learning.

Further, if it was an option to combine the required 3 months work experience and 12 month thesis and replaced with 9 months labwork and writing and 3 months in the field - students would find this attractive

\section{Surprising Events (Question 9)}

Some peers were surprised by the slowness of progress and it sometimes felt that way, although five years from conception to commercialisation does not seem that bad. What is probably true, however, is that a lot of effort was necessary to achieve this progress, maybe normal when dealing with many junior learners. The success (two international awards, competitive research funding and a lot of spons. Stud also reality. Students do not like the higher worked ends to bring. In fact, Ramsden compared different academic compartments and noted a correlation between a heavy workload (normal in engineering) with lack of responsible choice over learning (Ramsden 1992). While such projects belong to engineering, it may well be that those students find it the most difficult to make the transition from coursework to such learner centred projects.

\section{Other Comments (Question 10)}

It was described as commendable that students participate in applied research to appreciate relevance of their education. Other comments addressed team building skills, enthusiasm, the fact that mos university projects end as a thesis in the library but this one is getting commercialised" - yet there is a warning comment that such a project could be to the detriment of student's 'other' learning activities. This a ain demonstrates the limited acceptance amongst some peers and the attachment to 'nortes. This agein de (nespite (team building skill developed, students show considerable enthusiasm and enjoy themselves, all these features lead to successful learning experience".

A comment to break goals up into smaller activities with greater supervisor involvement is a pul towards a more directed approach. Ideally the students would like to be given small tasks that they are told how to accomplish. It is true that with regards to efficiency of outcomes and getting some students started this may be beneficial. In the extreme, this is however a move towards spoon feeding which the project aims to counter-act. In self-directed learning, learners do need to define their own goals, draw on available resources and judge success (Boud 1987). The teacher provides the environment in which learning can take place which is in this case the project infrastructure and the sense of 'feeling lost an not knowing to do' may contribute more to a students understanding of his or her learning than the successful accomplishment of a minor project task.

It was picked up by peers that such projects are a brilliant marketing tool for environmental engineering- after years of low student numbers - which confirms that much more such activities are required and "the fact that it can ultimately save lives makes it outstanding" and of course "fondes memories of the hot chilli beans that even the very hungry students didn't want to eat". Harsh conditions indeed!

\section{INSTRUCTOR DISCUSSION}

Leading such a project, an instructor experiences a range of emotions with regards to studen involvement and general project progress, varying from an intense sense of fulfilment or even a sense of a dream coming true to utter frustration. Positive emotions were associated with the two longer field trials, seeing the system perform well and students contributing with excitement as well as when accompanying students to an award ceremony. Students taking ownership of the project and even 
stating that their involvement in the project has shaped their future career choice has been extremely rewarding. The other end of the spectrum was generally associated with students and staff not wanting rewarding. The other end of the spectrum was generally associated with students and staff not wanting
to put the effort in, treating the project as last in line over conventional coursework and during team to put the effort in, tert
conflict and 'politics'.

Having retained very little of the facts learned during several years of coursework ourselves and finding lecture notes quite inaccessible to solve real life problems, our motivation has been to teach students more useful skills and encourage them to find out more about a particular area of engineering and hence create an in depth learning experience. The skill of persistence and the need to often give up sleep and jump hurdles that appear insurmountable cannot be taught in a classroom context and is a best experienced to the days prior to thesis submission. Experiencing such situations is extremely challenging but an important preparation to industry tasks such as project commissioning when challening but initially chose to contribute to the project. It is possible that the younger undergraduate students in particular, were overwhelmed by the required independence (as opposed to the usually tutor instructed learning in conventional practical learning situations), the need to spend time and energy on an activity that does not provide immediate academic benefits and lack of experience with design have bee understandable hurdles. For more advanced students, such as those working on final year projects or overseas practicum students, the experience was different; the project was the full time focus of their activities and hence substantial contributions and progress have been made. Those students have been able to adapt more easily to hands off supervision. Combining both groups of students has resulted in frustration as the voluntary students have not been able to commit a continuous and predictable effort. It hence appears that is not so much the lack of supervisor access, but possibly the lack of academic benefit that inhibited effective participation and hence learning.

Being part of the team was a primary contribution by students and in most cases this meant a significant amount of sometimes tedious and boring labour. The contributions of both students and significant an the teant of so instructors are summarised in Table 1 . In early project stages selected students contributed significantly to system design and construction in the absence of access to technical support. During optimisation and research experiments long hours of running the system, sampling and data taking reflected the reality of experimental research. During field trials this was intensified with harsh environments and long hours due to time limitations and delays due to expectable difficulties. Those experiences wer difficult yet reflect the realities of field work, especially those of remote locations, and gave a mild introduction of what is to expect in developing country situations. It is clear that not all students are suited to such experiences and careful selection as well as preparation (including a thorough risk assessment) is required. Clearly, the students were most engaged during the field trials and if a studen was actively involved in prototype design the optimisation also captured attention visibly. Team conflict needed better guidance. It is well recognised that projects are not likely to be successful if serious personal conflicts exist before the start of a project (Moore and Berry 2001), yet Denton (Denton 1997) points out that team effectiveness is not correlated with team harmony and that conflic can be very fruitful. Denton further outlines that students have a preference for a more cooperative style of organisation over the appointment of a leader which allows different team members to take on leadership roles at different times (Denton 1997). Possibly the appointment of a specific student manager was not necessary and leaving roles undefined may have prevented some of the territoria fighting observed. Brunetti et al. also reported "unfamiliar challenges with regards to group dynamics" for a project-based learning initiative (Brunetti et al. 2003). As a teacher, it may have been necessary to take a more involved role in the conflict at this point and discipline the two male students or reques them to leave the project. Further, more attention should have been paid to team building. Consulting resources such as "The Team Developer" (McGourty and de Meuse 2001) and sharing those with both the project manager may be advisable. While the team made progress with interacting with students from different disciplines as well as cultures, effective team membership was a challenge and gender differences remained a problem. Firstly, there was no tolerance of a female student being chosen over a male student for the leading role, there was also a clear observation that when technical hurdles became high many female students withdrew and in our assessment this was mostly a confidence issue. Here our role as teachers is one of encouragement and patience, although it is interesting to note here that some of the female students felt this encouragement and support very strongly.

In terms of technical skills, the students struggled with the application of (often absent) engineering knowledge. It was clear that the majority of students had little knowledge of even basic principles related to the project. Provision of reading materials was not successful as few students were willing to read books or related publications. This confirms the need outlined by Perrenet $e t$ al. who indicated that the learning requires "a subtle process of guided co-operative learning [...], one which shares some of the characteristics of PBL, but requires smaller groups and more structuring by the teacher" (Perrenet $e t$ the characteristics of PBL, but requires smaller groups and more structuring by the teacher" (Perrenet $e t$
al. 2000). While this approach was difficult in the initial stages of the project, later with less students who were able to spend more time on the project this was achieved through fortnightly one to one meetings. However, those students had a better technical background being close to the completion of their degrees, were more mature and were working on the project full time. To fill in for reading that the students were not prepared to do a lecture was given outlining principles of the technology to be applied.

Interacting with industry was exciting for all involved, in particular to foster multi-institutional as well as multi-disciplinary teams and quality improvement (Massay et al. 1995). This industry link has bee a challenge when deadlines were near impossible to meet, staffing problems prevailed during a critica project phase and a suitable $\mathrm{PhD}$ candidate could not be identified. Here the academic constraints can make it extremely difficult to match the industrial commercialisation agenda. However, seeing student finalise a system and present drawings is exciting and very satisfying and an important aspect for all involved is the project management exposure students get: regular project meetings, laboratory inspections, progress reports, project management through timelines and deliverables as well as communicating to industry how education takes place which has been a fruitful exchange.

\section{Conclusions}

After five years of a sustainable design project that has started with a concept idea and now achieved commercialisation, many students have been involved in this learning and research initiative. Reflecting on the initial project motivations which were to contribute to solving the water provision crisis, inspire students to contribute to solving significant global problems and planting a seed of change as well as adapting the more difficult to teach graduate attributes, taking stock allows us to report partial success.

Steps towards solving the water provision crisis have been made; in early 2006 a first system will be launched by the industry partner that has the ability to provide safe drinking water without requirement launched by the industry partner that has the ability to provide safe drinking water without requiremen of an electricity grid, no matter how contaminated the water source. Students have been inspired an several have communicated that they will continue working in the water industry. One can only hope that vision and determination with drive those students to make major contributions for a better future Planting a seed of change is more difficult to evaluate. Evidence of seeding is only then apparent when seedlings surface and convince through healthy growth. An observation that inspires hope is that more and more agencies engage in sustainability and human development marketing activities. Awards an 
prizes are created that motivate such projects to exist, new projects to be created and small amounts of prize monies act as seed funding for more substantial support. Funding agencies, such as the Australian Research Council, recognise the need for support of technology for sustainability and human development through supporting regional areas.

Learning has demonstrated that many graduate attribute characteristics were communicated an enhanced in project participants. Further, it appears that students who have been involved in such projects get credit for their voluntary contributions when on the job market- skills obtained from such projects are well recognised and in high demand. Those students will be the agents for change in decision making bodies such as governments, non-government organisations and aid organisations as well as those bringing along the general public. May future projects be created and reflective learning enhance the effectiveness of teams involved and the implementation in target communities an developing countries.

\section{ACKNOWLEDGEMENTS}

As usual students are the best teachers. We would like to thank those who have contributed, especially the many who have stayed in touch years after their launch into the real world. Thank you Michelle Grossbach, Janet Salem, Long Nghiem, Wes McCombe, Matt Daly, Tracey Hamer Christian Remy, Laurent Masson, Dorji Tsewang, Noriaki Endo, Deborah Lam, Lorien Martin, an Melanie Werner. Thank you also to our colleagues Andreas Broeckmann, Brian Uy, Michael Boyd Ian Porter, George Nawar, Andrew Moore as well as Mona McKenzie and Luke Scott as members of the broader community. Prof Adrian Lee from the University of New South Wales is thanked for supporting the Graduate Certificate of University Learning and Teaching studies of both authors.

\section{REFERENCES}

Azapagic, A., S. Perdan and D. Shallcross, How much do engineering students know about sustainable development? The findings of an international survey and possible implications for the
engineering curriculum. European Journal of Engineering Education, 2005, 30(1), 1-19.

Beder, S., The New Engineer: Management and Professional Responsibility in a Changing World. Pages, 1998 (MacMillan: Melbourne)

Boud, D., A facilitator's view of adult learning. In edited by D. Boud and V. Griffin, 1987 (Kogan Page: London).

Brookfield, S. D., Grounding teaching in learning. In edited by M. W. Galbraith, 33-56, 1991 (Krieger: Florida)

Brookfield, S. D., Becoming a critically reflective teacher. Pages, 1995 (Jossey-Bass Inc.: San Francisco, CA).

Brunetti, A. J., R. J. Petrell and B. Sawada, SEEDing sustainability: Team preoject-based learning enhances awareness of sustainability at the University of British Columbia, Canada. International Journal of Sustainability in Higher Education, 2003, 4(3), 210-217.

Denton, H. G., Multidisciplinary team-based project work: planning factors. Design Studies, 1997, 18(2), 155-170.

Dym, C. L., A. M. Agogino, O. Eris, D. D. Frey and L. J. Leifer, Engineering design thinking, teaching and learning. Journal of Engineering Education, 2005, 94(1), 103-120.

Eckersley, R., Dreams and expectations: young people's expected and preferred futures and their significance for education. Futures, 1999, 31, 73-90.

Felder, R. M. and R. Brent, The intellectual development of science and engineering students. Part 2 . Teaching to promote growth. Journal of Engineering Education, 2004, 93(4), 279-291.
Froyd, J. E. and M. W. Ohland, Integrated engineering curricula. Journal of Engineering Education, 2005, 94(1), 147-164

Galbraith, M. W., Becoming a skillful college teacher: some principles to practice. Issues \& Inquiry in College Learning and Teaching, 1996, Summer, 4-13.

Gleick, P. H. (2002). Dirty water: estimated deaths from water related diseases 2000-2020, Pacific Institute for Studies in Development, Environment, and Security

Hyde, R. A. and B. W. Karney, Environmental Education Research: Implications for Engineering Education. Journal of Engineering Education, 2001, April 2001, 267-276.

IEAust, Manual for the Accreditation of Professional Engineering Programs. Available online at: www.ieaust.org (accessed Retrieved 1509 2004).

Jerram, C., Applying adult education principles t university teaching, in Annual HERDSA Conference, 2002, 369-375.

Johnson, D. W., R. T. Johnson and K. A. Smith, Active learning: Cooperation in the college classroom. Pages, 1998 (Interaction Books: Edina, MN)

MacKinnon, M. M., Conversion to problem-based learning: a comparison of three approaches to curriculum reform, in Annual International Conference, 1999.

Massay, L. L., S. J. Udoka and B. Ram, Industry-university partnerships: A model for engineering education in the 21st century. Computers and Industrial Engineering, 1995, 29(1-4), 77-81.

Masson, L., B. S. Richards and A. I. Schäfer, System design and performance testing of a hybrid membrane photovoltaic desalination system. Desalination, 2005, 179, 51-59.

McGourty, J. and K. P. de Meuse, The team developer: An assessment and skill building program. Pages, 2001 (Wiley.

Miller, N. and D. Boud, Animating learning from experience. In edited by D. Boud and N. Miller, 3-13, 1995 (Routledge: London and New York).

Mitchell, J. E., J. Smith and A. J. Kwenyon, 'It's not for lazy students like me.' International Journal of Electrical Engineering Education, 2005, 42(1), 41-51.

Moore, D. and F. Berry, Industrial sponsored design projects addressed by student design teams. Journal of Engineering Education, 2001, 90(1), 69-73.

Paten, C. J. K., N. Palousis, K. Hargroves and M. Smith, Engineering sustainable solutions program: critical literacies for engineers portfolio. International Journal of Sustainability in Higher Education, 2005, 6(3), 265-277

Perdan, S. and A. Azapagic, Sustainable engineering design: an interative multimedia case study. International Journal of Sustainability in Higher Education, 2003, 4(1), 33-43.

Perrenet, J. C., P. A. J. Bouhuijs and J. G. M. M. Smits, The Suitability of Problem-based Learning for Engineering Education: theory and practice. Teaching in Higher Education, 2000, 5(3), 345358 .

Rammelt, C. F. and J. Boes, Arseniv mitigation and social mobilisation in Bangladesh. International Journal of Sustainability in Higher Education, 2004, 5(3), 308-319.

Ramsden, P., Learning from the student's perspective. In edited by, 1992 (Routledge: London and New York).

Ravesteijn, W., E. de Graaf and O. Krosen, Engineering the future: the social necessity of communicative engineers. European Journal of Engineering Education, 2006, 31(1), 63-71.

Richards, B. S., L. Masson, A. Broeckmann and A. I. Schäfer, Field performance of a 1000 litre/day PV-powered desalination system, in ISES Solar World Congress,2005, paper no. 1663.

Richards, B. S., L. Masson and A. I. Schäfer, Laboratory and field performance of a small scale brackish water desalination system powered with solar energy. Journal of Engineering for Sustainable Development: Energy, Environment, and Health, (submitted 07/2006). 
Published as: Schäfer, A.I. ; Richards, B.S. (2007) From Concept to Commercialization: Involving Students in a Sustainable Engineering Innovation Project, European Journal of Engineering Education, Volume 32, Issue 2 May 2007 , pages $143-165$ DOI: $10.1080 / 03043790601118689$

Richards, B. S., C. Remy and A. I. Schäfer, Sustainable drinking water production from brackish sources using photovoltaics, in Proc. 19th European Photovoltaic Solar Energy Conf.,2004, $3369-3372$

Richards, B. S. and A. I. Schäfer, Design considerations for a solar-powered desalination system for remote communities in Australia. Desalination, 2002, 144, 193-199.

Richards, B. S. and A. I. Schäfer, Photovoltaic-powered Desalination System for remote Australian Communities. Renewable Energy, 2003, 28, 2013-2022.

Rouvris, S., J. Ormrod, G. Landrac, J. Mallet, J.-M. Gilliot, A. Thepaut and P. Tremenbert, A mixed project-based learning framework: preparing and

developing student competencies in a French Grande Ecole. European Journal of Engineering Education, 2006, 31(1), 83-93.

Schäfer, A. I., A. Broeckmann and B. S. Richards, Membranes and renewable energy - A new era of sustainable development for developing countries. Membrane Technology, 2005, Nov, 6-10.

Schäfer, A. I., C. Remy and B. S. Richards, Performance of a small solar-powered Hybrid Membrane System for Remote Communities under varying Feedwater Salinities, in 4th IWA World Water Congress, 2004

Schäfer, A. I. and B. S. Richards, Testing of a hybrid membrane system for groundwater desalination in an Australian national park. Desalination, 2005, 183, 55-62.

Seat, E., J. A. Parsons and W. A. Poppen, Enabling engineering performance skills: A program to teach communication, leadership, and teamwork. Journal of Engineering Education, 2001, Jan 2001, $7-12$

Shuman, L. J., M. Besterfield-Sacre and J. McGourty, The ABET "Professional Skills" - Can they be Taught? Can they be Assessed? Journal of Engineering Education, 2005, 91(1), 41-55.

Terenzini, P. T., A. F. Cabrera, C. L. Colbeck, J. M. Parente and S. A. Bjorklund, Collaborative learning vs. lecture/discussion: Students' reported learning gains. Journal of Engineering Education, 2001, Jan 2001, 123-130

Thompson, N. S., E. M. Alford, C. Liao, R. Johnson and M. A. Matthews, Integrating undergraduate research into engineering: A communications approach to holistic education. Journal of Engineering Education, 2005, 94(3), 297-307.

Werner, M. and A. I. Schäfer, Social aspects of a solar-powered desalination unit for remote Australian communities. Desalination, 2006, (in press)
Tables

Table 1 Development of ROSI prototypes and role of students in different prototype stages

\begin{tabular}{|c|c|c|c|c|}
\hline STAGE & TASKS & STUDENT ROLES & TEACHER ROLES & PICTURE \\
\hline$I$ & $\begin{array}{l}\text { Proof of concept to students } \\
\text { and introduction to working in } \\
\text { an interdisciplinary team. } \\
\text { The project is student driven } \\
\text { with an appointed student } \\
\text { project manager. }\end{array}$ & \begin{tabular}{|l|} 
Student project manager, \\
and initially about 40 \\
students from varying \\
disciplines (Civil, \\
Environmental, Photovoltaics \\
Engineering \& Mechatronics) \\
contribute to various \\
subgroups such as technical \\
design, water quality, socio- \\
economic integration, \\
fundraising, etc.
\end{tabular} & $\begin{array}{l}\text { Communication of project idea, } \\
\text { setting of project constraints } \\
\text { (e.g. technology choice); } \\
\text { recruitment of student } \\
\text { manager and academic } \\
\text { advisory committee. Proposal } \\
\text { preparation and background } \\
\text { research for system } \\
\text { requirements. Provision of } \\
\text { information and industry } \\
\text { contacts to students. Advice to } \\
\text { student manager and liaison } \\
\text { with technical staff for ordering } \\
\text { etc. }\end{array}$ & \\
\hline II & $\begin{array}{l}\text { Development and construction } \\
\text { of prototype II which is } \\
\text { designed to meet the design } \\
\text { criteria specified for remote } \\
\text { community needs and is the } \\
\text { innovative basis for further } \\
\text { developments. } \\
\text { Student driven project } \\
\text { concluded with a } 9 \text { day field } \\
\text { trip to White Cliff, NSW and } \\
\text { the demonstration of prototype } \\
\text { II. }\end{array}$ & $\begin{array}{l}10-15 \text { students meet } \\
\text { irregularly, design prototype } \\
\text { while construction takes } \\
\text { place during field trial at } \\
\text { which } 9 \text { students participate. }\end{array}$ & $\begin{array}{l}\text { Liaison with industry partners } \\
\text { for provision of major system } \\
\text { components; location of } \\
\text { suitable pumps and } \\
\text { attendance of selected } \\
\text { subteam meetings, technical } \\
\text { design meetings in particular. } \\
\text { Budget responsibility, student } \\
\text { mentoring, hands of } \\
\text { involvement and provision of } \\
\text { support } \\
\text { Organisation, risk assessment } \\
\text { and leadership role in field trip. }\end{array}$ & \\
\hline III & $\begin{array}{l}\text { Research with prototype III } \\
\text { now with industry partner and } \\
\text { first custom desined pump. } \\
\text { Main research project targets: } \\
\text { - system testing and } \\
\text { optimization } \\
\text { - fouling and cleaning } \\
\text { - remote monitoring and } \\
\text { control } \\
\text { - pretreatment } \\
\text { - pump design }\end{array}$ & $\begin{array}{l}\text { Full time practicum student } \\
\text { to design and build prototype } \\
\text { III with better design. } \\
4 \text { Honours Students from } \\
\text { Environmental \& } \\
\text { Mechatronics Engineering } \\
\text { to carry out research } \\
\text { projects peripheral to system } \\
\text { development } \\
2 \text { Scholars students and one } \\
\text { volunteer also working on } \\
\text { research projects }\end{array}$ & $\begin{array}{l}\text { Supervision of research } \\
\text { students, technical liaison with } \\
\text { suppliers, industry links with } \\
\text { potential industry partner, } \\
\text { research design and revision, } \\
\text { documentation of progress and } \\
\text { research outcomes. } \\
\text { Organise for first year students } \\
\text { to attend overseas TV Gala } \\
\text { and Award ceremony (incl } \\
\text { funding). }\end{array}$ & \\
\hline
\end{tabular}


Published as: Schäfer, A.I. ; Richards, B.S. (2007) From Concept to Commercialization: Involving Students in a Sustainable Engineering Innovation Project, European Journal of Engineering Education, Volume 32, Issue 2 May 2007 , pages $143-165$ DOI: $10.1080 / 03043790601118689$

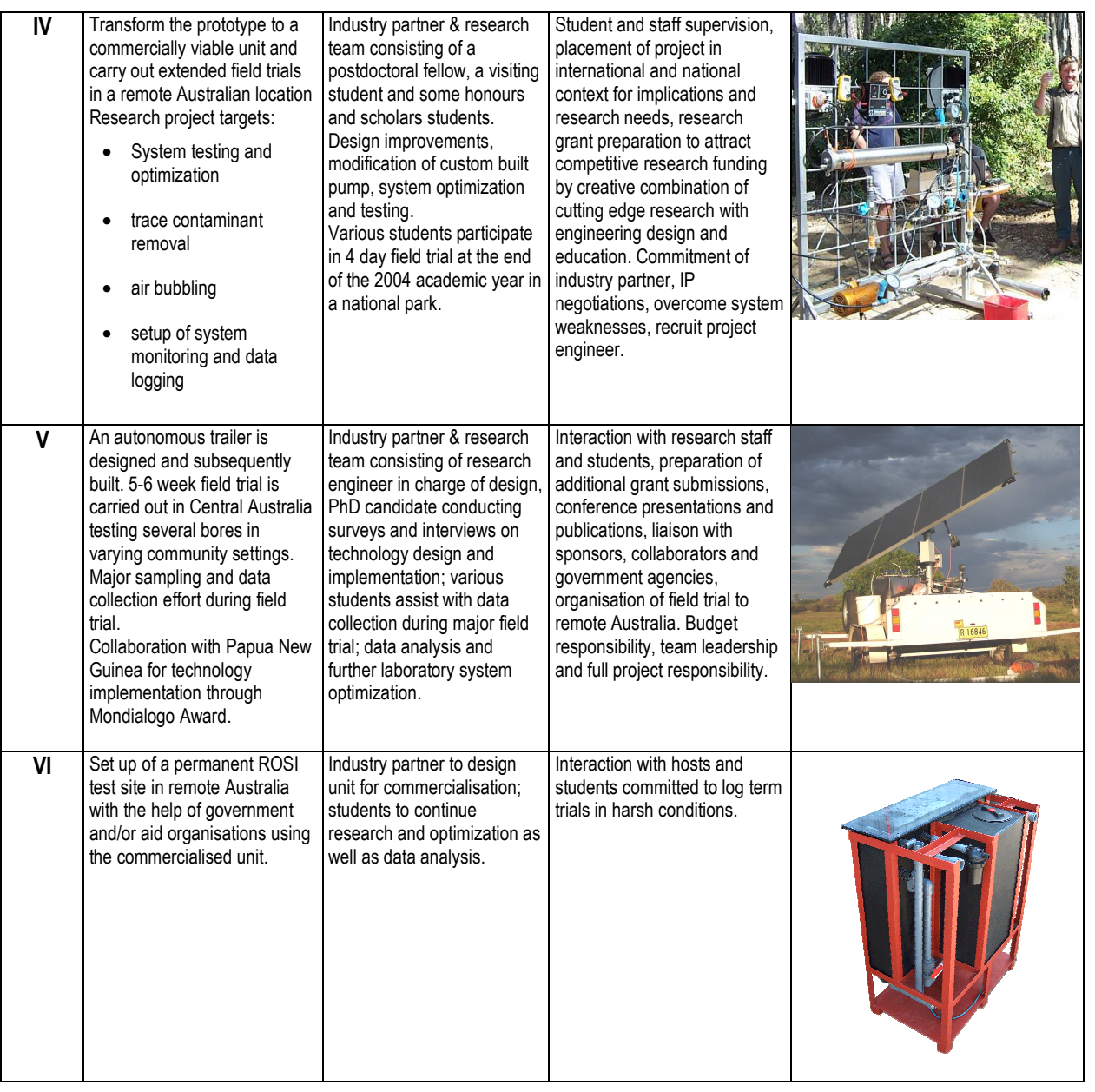

Table 2 Adapted Critical Incident Questionnaires (CIQs)

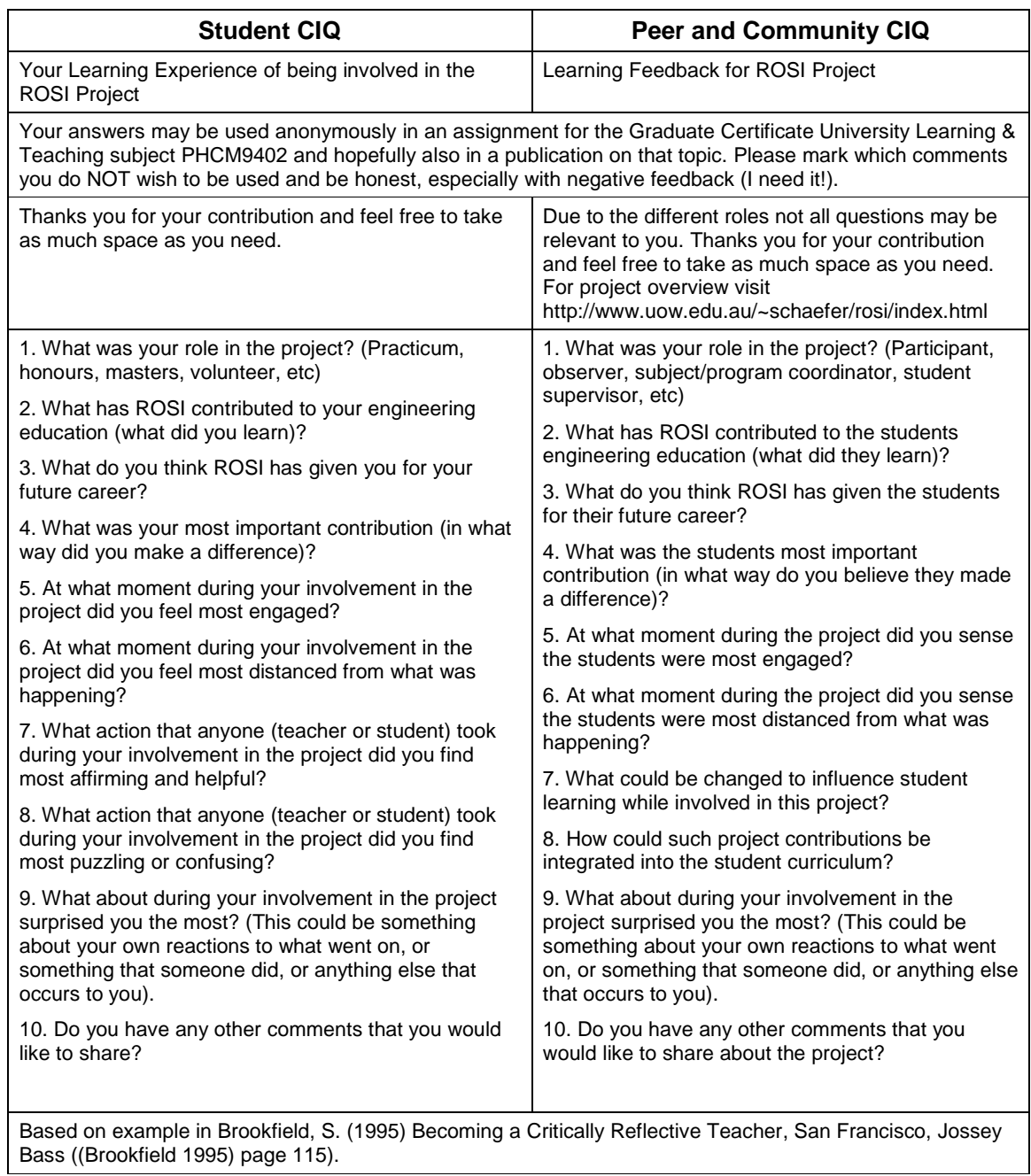


Published as: Schäfer, A.I. ; Richards, B.S. (2007) From Concept to Commercialization: Involving Students in a Sustainable Engineering Innovation Project, European Journal of Engineering Education, Volume 32, Issue 2 May 2007 , pages 143 - 165 DOI: 10.1080/03043790601118689

Author Bio's

Andrea Schäfer is the Chair of Environmental Engineering at Edinburgh University, UK. She has four engineering degrees from the University of Applied Sciences, Heilbronn, Germany, ESIGEC (University in Savoie), France and a PhD from UNSW in Australia with work experience in many countries. Her research areas are membrane technology, water recycling and developing country water supplies with a strength in interdisciplinary aspects involving social science, chemistry as well as innovative engineering design. Her passion for membrane technology and the knowledge that million of people die of poor drinking water has driven her to work in this field of water supplies for developing countries. Understanding that energy requirements of membrane processes are a hindrance to the successful and sustainable implementation of this technology has motivated the collaboration with a renewable energy expert to overcome this hurdle and make a real difference by telling students about it, motivating them to help solve this problem and ultimately saving many lives.

Bryce Richards is a Lecturer in the field of renewable energy at Heriot-Watt University (HWU), UK He holds a BSc in physics from Victoria University of Wellington, New Zealand, as well as a Masters and PhD from UNSW, Australia. Prior to his appointment at HWU he was employed at the Australian National University. He is interested in photovoltaic (PV) research and enjoys working at the interface between physics, chemistry, electrical engineering and mechanical engineering. His specific research interests include the application of luminescent materials to PV, the design and fabrication of solar cells, and renewable energy powered desalination systems. This latter research area provides a very rewarding link between R\&D and meeting people in remote communities who's lives can benefit by the provision of clean drinking water in a sustainable manner. The project also has the ability to capture the attention of students and motivate them do to research in this area. In April 2006, Dr. Richards was appointed as the managing editor for the journal Progress in Photovoltaics. 